\title{
Region-Specific Phosphorylation of Rabphilin in Mossy Fiber Nerve Terminals of the Hippocampus
}

\author{
György Lonart and Thomas C. Südhof \\ Department of Molecular Genetics and Howard Hughes Medical Institute, The University of Texas Southwestern Medical \\ Center, Dallas, Texas 75235
}

In mossy fiber synapses of the CA3 region of the hippocampus, long-term potentiation (LTP) is induced presynaptically by activation of cAMP-dependent protein kinase $A$ (PKA). Rab3A is a synaptic vesicle protein that regulates vesicle fusion and is essential for mossy fiber LTP. Rab3A probably acts via two effector proteins, rabphilin and RIM, of which rabphilin is an in vitro substrate for PKA. To test if rabphilin is phosphorylated in nerve terminals and if its PKA-dependent phosphorylation correlates with the PKA-dependent induction of LTP in mossy fiber terminals, we have studied the phosphorylation of rabphilin in synaptosomes isolated from the CA1 and CA3 regions of the hippocampus. Rabphilin was phosphorylated in both CA1 and CA3 synaptosomes. However, when we treated the CA1 and CA3 synaptosomes with forskolin (an agent that enhances PKA activity) or induced $\mathrm{Ca}^{2+}$ influx into synaptosomes with high $\mathrm{K}^{+}$, rabphilin phosphorylation was increased selectively in mossy fiber CA3 synaptosomes, but not in CA1 synaptosomes. In contrast, the phosphorylation of synapsin, studied as a control for the specificity of the region-specific phosphorylation of rabphilin, was augmented similarly by both treatments in CA1 and CA3 synaptosomes. These results reveal that the phosphorylation states of two synaptic substrates for PKA and CaM KII, rabphilin and synapsin, are regulated differentially in a region-specific manner, an unexpected finding because rabphilin and synapsin are similarly present in CA1 and CA3 synaptosomes and are colocalized on the same synaptic vesicles. The region-specific phosphorylation of rabphilin agrees well with the restricted induction of LTP by presynaptic PKA activation in mossy fiber, but not CA1, nerve terminals.

Key words: rab3; rabphilin; exocytosis; neurotransmitter release; synaptic transmission; synaptic vesicles; long-term potentiation; protein kinase A; CaM kinase II
Synapses transmit signals between neurons and constitute fundamental units of information processing in brain (Sheperd, 1990). The strength of synaptic transmission varies and is modulated by processes of synaptic plasticity, such as long-term potentiation (LTP). At least two forms of LTP are expressed in the hippocampus (for review, see Stevens, 1993; Nicoll and Malenka, 1995): (1) NMDA receptor-dependent LTP (CA1 LTP), most often studied in synapses of Schaffer collateral/commissural fibers on pyramidal CA1 neurons, and (2) NMDA receptor-independent LTP (CA3 LTP), expressed by mossy fiber synapses onto CA3 neurons. Both forms of LTP involve long-lasting increases in synaptic strength but are mechanistically distinct. CA1 LTP (NMDA receptor-dependent LTP) is induced postsynaptically by $\mathrm{Ca}^{2+}$ influx and activation of $\mathrm{Ca}^{2+}$, calmodulin-dependent protein kinase II (CaM KII) (for review, see Lisman et al., 1997). In contrast, CA3 LTP (NMDA receptor-independent LTP) is initiated presynaptically by activation of cAMP-dependent protein kinase A (PKA) (Huang et al., 1994; Weisskopf et al., 1994; Salin et al., 1996). Induction of CA3 LTP must involve changes in the $\mathrm{Ca}^{2+}$-triggered exocytosis of synaptic vesicles, but no presynaptic phosphoproteins that might be involved in LTP induction are known.

Received Aug. 25, 1997; revised Oct. 27, 1997; accepted Oct. 31, 1997.

This study was supported by a Human Frontier Science Program grant, National Institutes of Health Grant RO1-MH52804, and the Perot Family Foundation. We thank Drs. E. Kandel, R. Nicoll, R. Malenka, M. S. Brown, and J. L. Goldstein for invaluable discussions.

Correspondence should be addressed to Dr. Tom Südhof, Room Y5.322, University of Texas Southwestern Medical Center, 5323 Harry Hines Boulevard, Dallas, TX 75235.

Copyright (C) 1998 Society for Neuroscience $\quad 0270-6474 / 98 / 180634-07 \$ 05.00 / 0$
Considerable progress was made recently in the biochemical dissection and genetic analysis of the proteins that govern presynaptic function (for review, see Ferro-Novick and Jahn, 1994; Südhof, 1995; Martin, 1997). Among these proteins, rab3A and synapsins Ia and Ib are synaptic vesicle proteins with important functions in regulating exocytosis. Knock-out experiments showed that rab3A is required for limiting the amount of vesicle exocytosis per $\mathrm{Ca}^{2+}$ signal (Geppert et al., 1994, 1997) and is essential for CA3 LTP (Castillo et al., 1997). The requirement for rab3A in CA3 LTP was unexpected because rab3A is a ubiquitous synaptic protein that is not enriched in CA3 mossy fibers (Li et al., 1994). Rab3A acts by binding in a GTP-dependent manner to at least two putative effector proteins, rabphilin and RIM (Shirataki et al., 1993; Li et al., 1994; Wang et al., 1997). Rabphilin is an in vitro substrate for PKA (Fykse et al., 1995) and for CaM KII (Kato et al., 1994; Fykse et al., 1995), suggesting it might be involved in the rab3A-dependent generation of CA3 LTP.

Similar to rabphilin, synapsins are also substrates for PKA and CaM KII (for review, see Greengard, 1987). Synapsins are required for normal short-term synaptic plasticity and synaptic vesicle stability (Rosahl et al., 1993, 1995) but are not essential for CA1 and CA3 LTP (Spillane et al., 1995). The exact functions of synapsins are unknown; a morphometric analysis of synapses from mice lacking synapsins I and II showed no changes in synapse number or vesicle clustering (Rosahl et al., 1995), whereas major changes in these parameters were seen in a second study on a different mouse line lacking only synapsin I ( $\mathrm{Li}$ et al., 1995).

Despite the progress in the electrophysiological and biochemical analysis of synapses, little is known about the mechanisms involved in presynaptic regulation. One problem is that most 
preparations used to study presynaptic function electrophysiologically are inaccessible biochemically. A second problem is that it is unclear which synaptic proteins are phosphorylated in nerve terminals in correlation with functional changes. This gap in understanding is most striking for synapsins and rabphilin, which are the only currently known presynaptic PKA and CaM KII substrates, but for which the phosphorylation in nerve terminals either has not been studied yet (rabphilin) or has not been associated directly with a synaptic plasticity (synapsins). In the current study we have investigated the phosphorylation of rabphilin and synapsins in synaptosomes from hippocampal synapses with distinct properties, regular synapses from the CA1 region and large mossy fiber synapses from the CA3 region. Our results demonstrate that rabphilin is phosphorylated in a stimulationdependent and region-specific manner that correlates with mossy fiber LTP. This suggests a mechanism of presynaptic regulation that uses region-specific changes in the phosphorylation states of generally distributed synaptic proteins.

\section{MATERIALS AND METHODS}

Preparation of synaptosomes. CA1 and CA3 regions were dissected from rat hippocampus, using the minor and the hippocampal fissures as landmarks. Large mossy fiber synaptosomes were prepared by homogenizing the $\mathrm{CA} 3$ region manually in $1 \mathrm{~mm} \mathrm{MgSO}_{4}, 0.3 \mathrm{~m}$ sucrose, and $15 \mathrm{~mm}$ HEPES-NaOH, pH 7.4, to preserve the complex structure and large size of the mossy fiber terminals (Hajos et al., 1975; Terrian et al., 1988). The homogenate was passed through a series of nylon filters $(100,60$, and 40 $\mu \mathrm{m}$ mesh size) and centrifuged at $900 \times g$ for 10 min to selectively pellet large synaptosomes. The pellet was resuspended in $18 \%(w / v)$ Ficoll and $0.3 \mathrm{~m}$ sucrose and centrifuged at $16,000 \times g$ for $20 \mathrm{~min}$ to separate the synaptosomes that remained in suspension from contaminating nuclei. Synaptosomes were diluted with 4 vol of $0.3 \mathrm{M}$ sucrose and sedimented by centrifugation at $15,000 \times g$ for $20 \mathrm{~min}$ to remove the Ficoll before use. Small synaptosomes were prepared from the CA1 region by gradient centrifugation by a method modified from Nagy and Delgado-Escueta (1984). The crude mitochondrial fraction $\left(\mathrm{P}_{2}\right)$ was resuspended in $8.5 \%$ $(\mathrm{v} / \mathrm{v})$ Percoll suspended in $0.25 \mathrm{~m}$ sucrose and $5 \mathrm{~mm}$ HEPES-NaOH, $\mathrm{pH}$ 7.4 , and layered on top of an $12 \% / 20 \%$ Percoll step gradient in the same buffer. After centrifugation at $18,000 \times g$ for $30 \mathrm{~min}$, synaptosomes were recovered from the $12 \% / 20 \%$ Percoll interface. Percoll was removed by the addition of $30 \mathrm{vol}$ of $0.32 \mathrm{M}$ sucrose and centrifugation at $18,000 \times g$ for $20 \mathrm{~min}$. In a typical experiment $2 \mathrm{mg}$ of CA1 and $4 \mathrm{mg}$ of CA3 synaptosomal protein were isolated from seven rat brains.

Phosphorylation measurements. Synaptosomes (1 mg protein) were incubated with ${ }^{32} \mathrm{P}$-orthophosphate $(1 \mathrm{mCi})$ for $1 \mathrm{hr}$ at $37^{\circ} \mathrm{C}$ in phosphate-free aerated $\left(95 \% \mathrm{O}_{2} / 5 \% \mathrm{CO}_{2}\right)$ Krebs-Henseleit-HEPES buffer [KHH buffer; composition (in mM): $\mathrm{NaCl} 118, \mathrm{KCl} 3.5, \mathrm{CaCl}_{2}$ 1.25, $\mathrm{MgSO}_{4} 1.2, \mathrm{KH}_{2} \mathrm{PO}_{4} 1.2, \mathrm{NaHCO}_{3} 25, \mathrm{HEPES}-\mathrm{NaOH} 5$ at $\mathrm{pH}$ 7.4 , and glucose 11.5] containing $0.1 \mathrm{mM} \mathrm{CaCl}_{2}$. The tubes were flushed with $95 \% \mathrm{O}_{2} / 5 \% \mathrm{CO}_{2}$ every $15 \mathrm{~min}$. Free ${ }^{32} \mathrm{P}$-orthophosphate was removed by pelleting the synaptosomes at $1000 \times g$ for $5 \mathrm{~min}$ at $4^{\circ} \mathrm{C}$. After washing, synaptosomes were resuspended in cold aerated $\mathrm{KHH}$ buffer (final concentration $0.2 \mathrm{gm} / 1$ protein) and equilibrated for $10 \mathrm{~min}$ at $37^{\circ} \mathrm{C}$. Protein phosphorylation was studied under four treatment conditions. For controls and treatment with forskolin alone, synaptosomes $(225 \mu \mathrm{l})$ were added to $25 \mu \mathrm{l}$ of KHH buffer containing $1 \%$ DMSO without or with $0.5 \mathrm{~mm}$ forskolin, and the reactions were stopped after $5 \mathrm{~min}$. For treatment with elevated $\mathrm{K}^{+}$alone or in combination with forskolin, synaptosomes $(225 \mu \mathrm{l})$ were added to 12.5 $\mu \mathrm{l}$ of $\mathrm{KHH}$ buffer containing $2 \%$ DMSO without or with $1 \mathrm{~mm}$ forskolin, respectively. Reactions were incubated for $4 \mathrm{~min}$; then 12.5 $\mu \mathrm{l}$ of $0.4 \mathrm{M} \mathrm{KCl}$ in $\mathrm{KHH}$ buffer was added, and reactions were stopped after an additional $1 \mathrm{~min}$. Reactions were stopped by the addition of $100 \%$ TCA ( $7.5 \%$ final concentration) for analysis of total protein phosphorylation, or by the addition of $1 \%$ SDS with (in mM) 1 EGTA, 1 EDTA, $50 \mathrm{NaF}$, and $10 \mathrm{Na}_{4} \mathrm{P}_{2} \mathrm{O}_{7}$ (final concentrations) for immunoprecipitations. For analysis of total protein phosphorylation, TCA precipitates were washed with $90 \%$ ethanol and acetone, resuspended in $1 \times$ SDS-PAGE sample buffer, and analyzed by linear gradient SDS-PAGE and autoradiography. For immunoprecipitations, samples were adjusted to $0.17 \%$ SDS, $1 \%$ Triton $\mathrm{X}-100$, plus (in $\mathrm{mm}$ ) 10

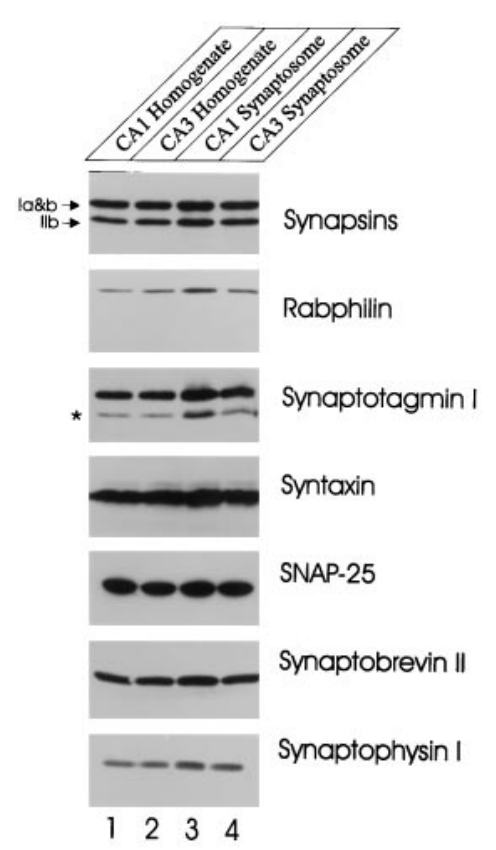

Figure 1. Immunoblot analysis of synaptic proteins in CA1 and CA3 synaptosomes. Equivalent amounts of protein $(10 \mu \mathrm{g} / \mathrm{lane})$ from the indicated fractions were analyzed by SDS-PAGE and immunoblotting, with antibodies to the proteins shown. Signals were visualized by enhanced chemiluminescence. An asterisk in the synaptotagmin 1 immunoblot marks the position of a major proteolytic breakdown product commonly observed in immunoblots for synaptotagmin.

HEPES-NaOH, pH 7.4, $100 \mathrm{NaCl}, 50 \mathrm{NaF}, 1$ EGTA, 1 EDTA, and 1 PMSF with $1 \mathrm{mg} / 1$ pepstatin, $10 \mathrm{mg} / 1$ leupeptin, and $10 \mathrm{mg} / 1$ antipain. Particulate matter was removed by centrifugation $(20,000 \times g$ for 10 min, twice), and serum (1\% v/v final concentration) was added. Rabphilin was immunoprecipitated with antibodies raised against a recombinant GST-rabphilin fusion protein (I734; Li et al., 1994), and synapsins were raised with an antibody against the N-terminal sequence of synapsins (E028; Rosahl et al., 1995). Antigen-antibody complexes were recovered by incubation with $50 \mu \mathrm{l}$ of a $50 \%$ slurry of protein A-Sephadex beads for $45 \mathrm{~min}$ and subsequent centrifugation at $1000 \times$ $g$ for $5 \mathrm{~min}$. The beads were washed four times in $10 \mathrm{~mm}$ HEPES$\mathrm{NaOH}, \mathrm{pH} 7.4,0.15 \mathrm{~m} \mathrm{NaCl}, 1 \mathrm{~mm}$ EDTA, and $0.5 \%$ Triton X-100; resuspended in SDS sample buffer; and analyzed by SDS-PAGE. After staining and destaining, phosphoproteins were visualized by autoradiography. ${ }^{32} \mathrm{P}$ incorporation was quantified with a PhosphorImager (Molecular Dynamics, Sunnyvale, CA). Data from multiple experiments performed in duplicate were pooled, and the significance of changes was evaluated statistically with the Kruskal-Wallis one-way ANOVA, followed by Dunnett's test for pairwise multiple comparisons, with a significance level of $p<0.05$.

\section{RESULTS}

\section{Purification of CA1 and CA3 synaptosomes from the hippocampus}

To study the differential regulation of hippocampal synapses biochemically, we purified synaptosomes from the CA1 and CA3 regions of the hippocampus. We dissected the CA1 and CA3 regions from rat brains, isolating regular "small" synaptosomes from the CA1 region by standard techniques and large mossy fiber synaptosomes from the CA3 region by making use of their large size (see Materials and Methods). To determine whether the protein composition of the two types of synaptosomes is similar, we analyzed them by immunoblotting with antibodies to several presynaptic proteins (Fig. 1). No major differences in the relative levels of different proteins were found. 


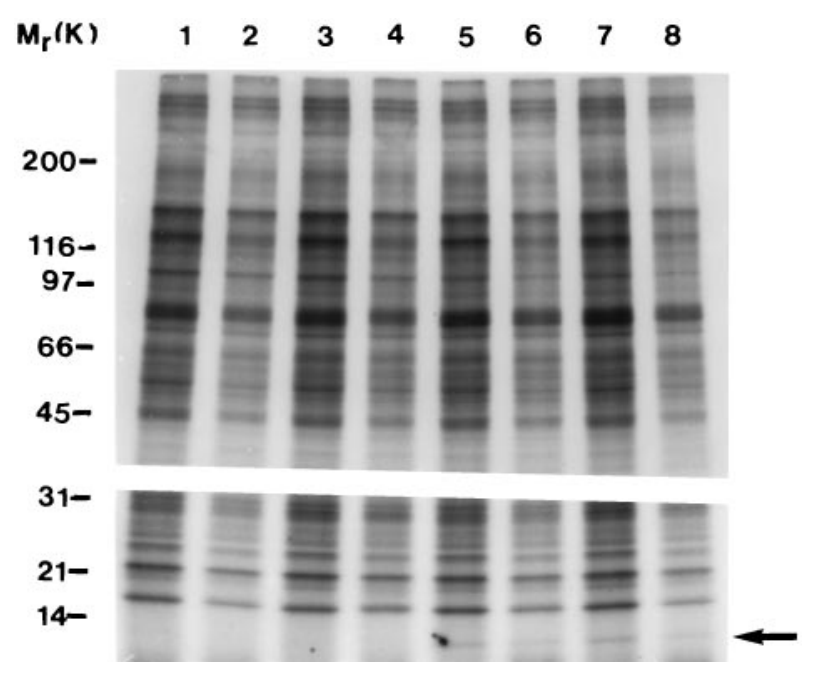

Figure 2. Protein phosphorylation in CA1 and CA3 synaptosomes. Analysis of total protein phosphorylation in synaptosomes from the CA1 (lanes $1,3,5,7$ ) and the CA3 (lanes 2, 4, 6, 8) region. Synaptosomes were treated as follows: lanes 1, 2, control; lanes 3, 4, $50 \mu \mathrm{M}$ forskolin (5 min); lanes 5, $6,20 \mathrm{mM} \mathrm{K}^{+}(1 \mathrm{~min})$; lanes $7,8,50 \mu \mathrm{M}$ forskolin $(5 \mathrm{~min})$ and $20 \mathrm{~mm} \mathrm{~K}^{+}$ (1 min). Numbers on the left indicate positions of molecular weight markers (in $\mathrm{kDa}$ ). The top part of the autoradiogram was exposed for 13 $\mathrm{hr}$ and the bottom part for $60 \mathrm{hr}$ to visualize the $10 \mathrm{kDa}$ band, the phosphorylation for which is induced by $\mathrm{K}^{+}$(arrow).

\section{Protein phosphorylation in CA1 and CA3 synaptosomes}

To gain insight into potential differences between CA1 and CA3 synaptosomes in the phosphorylation of proteins by PKA, we first analyzed the overall pattern of protein phosphorylation in ${ }^{32}$ P-labeled synaptosomes. Synaptosomes were analyzed by SDS-PAGE and autoradiography either under control conditions or after treatment with forskolin, elevated $\mathrm{K}^{+}$, or a combination of forskolin and elevated $\mathrm{K}^{+}$. Forskolin was used because it activates adenylate cyclase, thereby increasing cAMP levels and PKA activity. Elevated $\mathrm{K}^{+}$was used because it causes $\mathrm{Ca}^{2+}$ influx into synaptosomes, thereby activating CaM KII and other kinases. Thus the two treatments activate two different but overlapping signal transduction pathways in synaptosomes, one of which (the PKA pathway) is required for CA3 LTP, but not CA1 LTP.

No major differences in the phosphoprotein pattern of CA1 and CA3 synaptosomes were observed under resting conditions, providing additional evidence that they are similar in composition (Fig. 2). Forskolin did not induce major alterations in the phosphorylation patterns of either CA1 or CA3 synaptosomal proteins. $\mathrm{K}^{+}$elevation increased phosphorylation of a protein in the $10 \mathrm{kDa}$ molecular weight range in both types of synaptosomes but otherwise caused only minor changes (arrow in Fig. 2). We also analyzed synaptosomal protein phosphorylation by twodimensional gel electrophoresis after various stimulation conditions to confirm these findings (Garrels, 1979). Although the two-dimensional gels improved resolution, we again observed no differences between CA1 and CA3 synaptosomes (data not shown). These results suggest that CA1 and CA3 synaptosomes are similar in composition and that forskolin treatment and $\mathrm{K}^{+}$ depolarization do not cause major changes in the phosphorylation of abundant proteins.

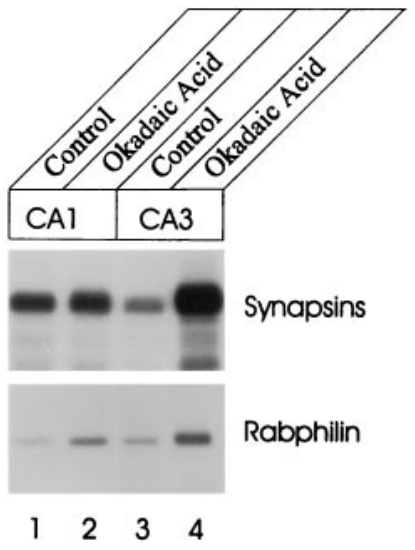

Figure 3. Okadaic acid increases synapsin and rabphilin phosphorylation in CA1 and CA3 synaptosomes. ${ }^{32} \mathrm{P}$-labeled CA1 and CA3 synaptosomes were incubated for $5 \mathrm{~min}$ in control buffer or buffer containing okadaic acid $(50 \mu \mathrm{M})$ and then subjected to immunoprecipitations with antibodies to synapsins (top) and rabphilin (bottom). Shown is a representative autoradiogram.

\section{Phosphorylation of rabphilin and synapsins in CA1 and CA3 synaptosomes}

We next studied whether rabphilin is phosphorylated in the two types of synaptosomes as a system resembling in vivo conditions. For these and the following experiments, we used synapsins as well characterized synaptic phosphoproteins as positive controls. We immunoprecipitated rabphilin and synapsins from resting ${ }^{32} \mathrm{P}$-labeled synaptosomes and from synaptosomes that were treated with okadaic acid. Okadaic acid was applied at a concentration of $50 \mu \mathrm{M}$ at which it is an inhibitor of serine/threonine protein phosphatases $1,2 \mathrm{~A}$, and $2 \mathrm{~B}$. At this concentration okadaic acid nonspecifically increases protein phosphorylation. The experiments with okadaic acid revealed that rabphilin and synapsins were phosphorylated in both CA1 and CA3 synaptosomes and that okadaic acid greatly increased the phosphorylation states of both proteins in the two types of synaptosomes (Fig. 3). Thus rabphilin is phosphorylated in synaptosomes similar to synapsins. However, phosphorylation and immunoprecipitation experiments can be quite variable because they involve multiple procedures, and single experiments are insufficient for evaluating magnitudes of changes. Therefore, we quantitated the degree of rabphilin and synapsin phosphorylation in multiple independent experiments with a phosphoimager. The increase in phosphorylation induced by okadaic acid was calculated for each experiment relative to baseline phosphorylation.

Using this analysis, we found that okadaic acid increased both rabphilin and synapsin phosphorylation three- to fourfold in both types of synaptosomes (Fig. 4). These data quantitatively confirm the qualitative impression from the experiment in Figure 3, namely that rabphilin and synapsins are phosphoproteins in synaptosomes, the phosphorylation of which constantly turns over and therefore is enhanced by the addition of a phosphatase inhibitor. The overall phosphorylation signal is higher for synapsins than for rabphilin, presumably because synapsins are more abundant. However, the increase in phosphorylation induced by okadaic acid is similar for rabphilin and synapsins and not dramatically different between CA1 and CA3 synaptosomes. This indicates that at resting conditions the turnover rate of phosphorylation is comparable for the two proteins and the two types of synaptosomes. 

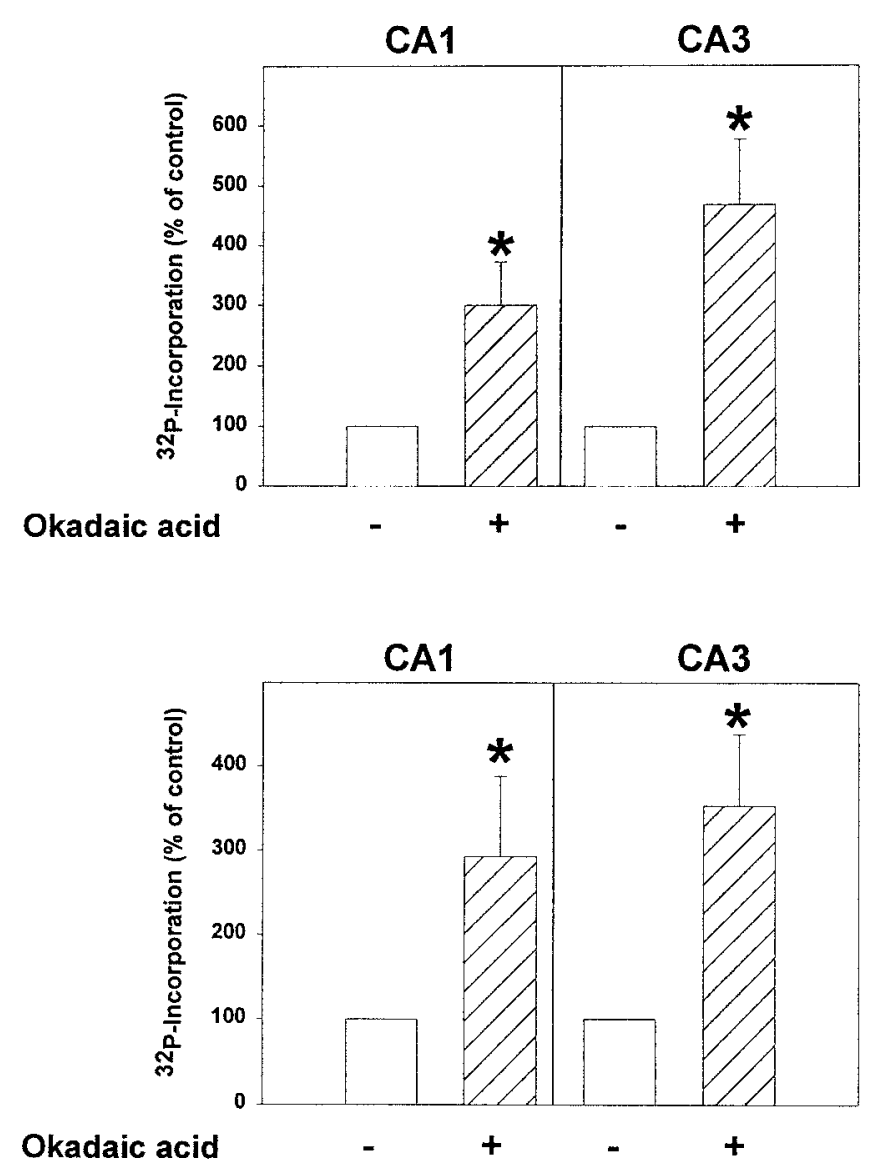

\section{Forskolin and high $\mathrm{K}^{+}$enhance rabphilin phosphorylation in CA3, but not in CA1, synaptosomes}

Next we investigated the regulation of rabphilin phosphorylation by PKA (activated by forskolin treatment) and by $\mathrm{Ca}^{2+}$. dependent protein kinases (activated by $\mathrm{Ca}^{2+}$ influx triggered by membrane depolarization in solutions with $20 \mathrm{~mm} \mathrm{~K}^{+}$). ${ }^{32} \mathrm{P}$ labeled synaptosomes from the CA1 and CA 3 regions were treated with four conditions: (1) control, (2) forskolin, (3) $\mathrm{K}^{+}$ depolarization, and (4) forskolin in combination with $\mathrm{K}^{+}$depolarization. We then immunoprecipitated rabphilin from the treated synaptosomes and quantified its phosphorylation by SDSPAGE and phosphoimager detection. To ensure that the immunoprecipitations were equally effective under various treatment conditions, we confirmed the presence of rabphilin in the immunoprecipitates by immunoblotting (data not shown). Because these experiments involved multiple procedures that might fluctuate randomly between experiments, we quantified phosphorylations in multiple independent determinations. In each experiment the phosphorylation of rabphilin was measured relative to baseline phosphorylation, and data from multiple experiments were analyzed statistically.

Forskolin induced a dramatic increase in rabphilin phosphorylation in CA3 synaptosomes (260-400\% increase), suggesting that it is a physiological substrate for PKA (Fig. 5). $\mathrm{K}^{+}$depolarization also enhanced rabphilin phosphorylation in CA3 synaptosomes (Fig. 5). $\mathrm{K}^{+}$depolarization only enhanced rabphilin phosphorylation in the presence of $\mathrm{Ca}^{2+}$ in the incubation medium, but not in its absence, suggesting that $\mathrm{Ca}^{2+}$ influx triggered by $\mathrm{K}^{+}$depolarization is essential for stimulating rabphilin phosphorylation. In contrast, forskolin-stimulated phosphorylation of

\section{Synapsins}

\section{Rabphilin}

Figure 4. Quantitative analysis of enhancement of rabphilin and synapsin phosphorylation by okadaic acid. The phosphorylation of synapsins and rabphilin in control synaptosomes and in synaptosomes treated with okadaic acid $(50 \mu \mathrm{M})$ was quantified by phosphoimager detection after immunoprecipitation and SDS-PAGE, as described in Figure 3. Data shown are mean \pm SEM from four independent experiments. Asterisks indicate that in both CA1 and CA3 synaptosomes the increase in the phosphorylation of synapsins and rabphilin is statistically significant. rabphilin was not dependent on $\mathrm{Ca}^{2+}$ (data not shown). The combination of forskolin with $\mathrm{K}^{+}$depolarization caused an additive increase in phosphorylation in the CA3 synaptosomes but only a small effect in CA1 synaptosomes. These observations suggest that rabphilin is a substrate for PKA and CaM KII not only in vitro but also in synaptosomes, a system resembling nerve terminals of living neurons.

Strikingly, forskolin had no significant effect on rabphilin phosphorylation in CA1 synaptosomes. The stimulatory effect of $\mathrm{K}^{+}$ on rabphilin phosphorylation also was restricted to synaptosomes from the CA3 region, and no effect was observed in CA1 region synaptosomes (Fig. 5). These results reveal that the phosphorylation of rabphilin is regulated differentially in different types of nerve terminals (CA1 vs CA3).

\section{Forskolin and depolarization-induced $\mathrm{Ca}^{2+}$ influx stimulate phosphorylation of synapsins}

The fact that forskolin and $\mathrm{Ca}^{2+}$ influx increase rabphilin phosphorylation in a region-specific manner is striking because okadaic acid increased phosphorylation of rabphilin in both types of synaptosomes (Fig. 4). This raises the question of whether for an unknown reason forskolin and $\mathrm{Ca}^{2+}$ influx may have been unable to activate kinases in the CA1 synaptosomes. To evaluate this concern, we analyzed the effect of forskolin and $\mathrm{Ca}^{2+}$ influx on the phosphorylation state of synapsins in both synaptosomes under conditions identical to those used for rabphilin.

Our results show that both forskolin and $\mathrm{K}^{+}$elevation stimulated synapsin phosphorylation and stimulated it equally in CA1 and CA3 synaptosomes (Fig. 6). The increase in synapsin phosphorylation was relatively small $(35-50 \%)$, as compared with the 
CA1

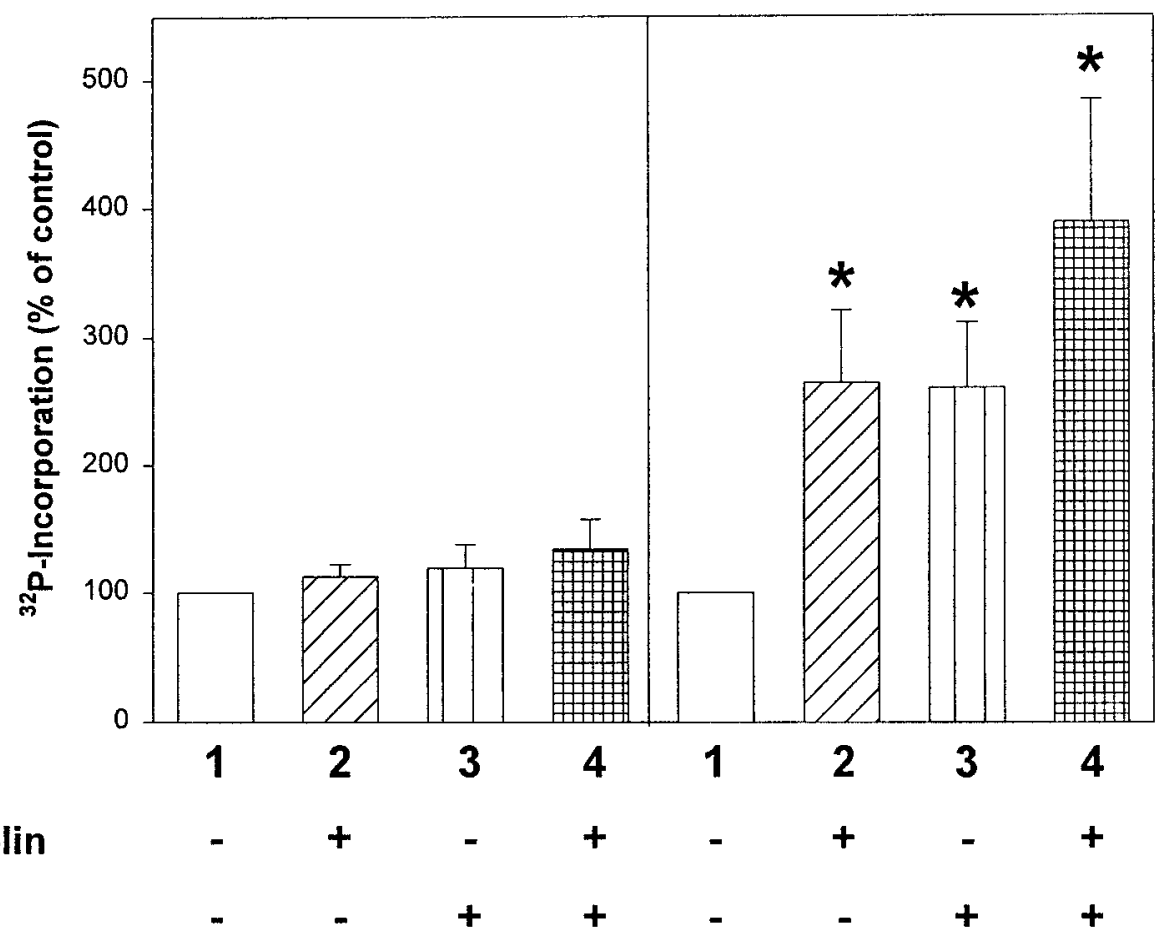

Figure 5. Modulation of rabphilin phosphorylation in CA1 and CA3 synaptosomes by forskolin and $\mathrm{K}^{+}$-induced $\mathrm{Ca}^{2+}$ influx. Rabphilin was immunoprecipitated from ${ }^{32} \mathrm{P}$-labeled CA1 or CA3 synaptosomes incubated under four treatment conditions: 1 , control (5 $\mathrm{min})$; 2, forskolin (50 $\mu \mathrm{M}$ for $5 \mathrm{~min})$; 3, control (4 min), followed by $20 \mathrm{~mm} \mathrm{~K}^{+}(1 \mathrm{~min})$ to induce membrane depolarization and $\mathrm{Ca}^{2+}$ influx; 4, forskolin (4 min), followed by forskolin combined with 20 $\mathrm{mM} \mathrm{K}^{+}(1 \mathrm{~min})$. After immunoprecipitations, samples were analyzed on an SDS-polyacrylamide gel, and the phosphorylation of immunoprecipitated rabphilin was quantitated on a phosphoimager. Data shown are mean \pm SEM from seven independent experiments performed in duplicate. Statistically significant changes are marked by asterisks.

\section{Forskolin $\mathrm{K}^{+}$}

increase in rabphilin phosphorylation observed in CA3 synaptosomes (260-400\%). However, the increase in synapsin phosphorylation under these mild stimulation conditions is statistically significant $(p<0.05)$ and similar to that observed by others previously (Wang et al., 1988). The fact that synapsin phosphorylation is increased equally in CA1 and CA3 synaptosomes demonstrates that the CA1 synaptosomes are responsive to stimulation and that the lack of an increase in rabphilin phosphorylation under our treatment conditions is not attributable to a failure of these synaptosomes to respond.

\section{DISCUSSION}

In presynaptic mossy fiber terminals of the CA3 region of the hippocampus, PKA activation induces a presynaptic form of LTP, which we refer to as CA3 LTP (Huang et al., 1994; Weisskopf et al., 1994). Recent studies have shown that, in mice lacking the synaptic vesicle protein rab3A, CA3 LTP cannot be induced normally (Castillo et al., 1997). This result directly proves a participation of the molecular machinery for vesicular exocytosis in CA3 LTP. It suggests that rab3A is, in an unknown manner, required for PKA-dependent long-term potentiation of neurotransmitter release. Rab3A itself is not a PKA substrate, suggesting that PKA does not act directly on rab3A. However, rab3A is thought to act by binding to effector proteins in a GTP-dependent manner, and one of its two known effectors, rabphilin, was shown previously to be a substrate for PKA in vitro (Fykse et al., 1995). In the present study we set out to address two questions: (1) Is rabphilin also phosphorylated by PKA in a system resembling nerve terminals of living neurons? (2) Is there a difference in the phosphorylation of rabphilin between CA1 and CA3 nerve terminals that correlates with the ability of PKA to induce LTP in mossy fiber synapses of the CA3 region, but not in Schaffer collateral/commissural fiber synapses of the CA1 region?

To resolve these questions, we have isolated synaptosomes, pinched-off nerve endings, from the CA1 and CA3 regions of the hippocampus and have analyzed the phosphorylation of rabphilin in these synaptosomes. Synapsin phosphorylation was studied as a control. We quantitatively compared the phosphorylation of rabphilin and synapsins to baseline phosphorylation states under four treatment conditions: (1) okadaic acid as a relatively nonspecific phosphatase inhibitor to induce a general increase in phosphorylation states, (2) forskolin as an activator of adenylyl cyclase to increase cAMP levels and PKA activity, (3) elevated $\mathrm{K}^{+}$to trigger $\mathrm{Ca}^{2+}$ influx into the synaptosomes to activate $\mathrm{Ca}^{2+}$-dependent kinases, and (4) a combination of forskolin and $\mathrm{K}^{+}$treatment.

Our data result in two basic conclusions. (1) Rabphilin is phosphorylated in synaptosomes, and its phosphorylation is increased several-fold by activations of PKA and by $\mathrm{Ca}^{2+}$ influx. This suggests that it constitutes a physiological substrate for PKA and for $\mathrm{Ca}^{2+}$-activated kinases, probably CaM KII. (2) Although rabphilin is phosphorylated and its phosphorylation is increased by a generic phosphatase inhibitor in both CA1 and CA3 synaptosomes, forskolin and $\mathrm{Ca}^{2+}$ influx enhance rabphilin phosphorylation only in $\mathrm{CA} 3$, but not in CA1, synaptosomes. The region-specific regulation of rabphilin phosphorylation parallels that of the action of PKA in inducing CA3 LTP. It is unlikely to be artifactual, because synapsin phosphorylation was increased similarly in both types of synaptosomes with forskolin and $\mathrm{K}^{+}$stimulation.

The region-specific phosphorylation of rabphilin is surprising because phosphorylated rabphilin and active PKA are present in both types of synaptosomes. These results reveal an unexpected regional specialization of protein phosphorylation in nerve terminals, the first demonstration of region-specific phosphorylation of a synaptic protein. The region-specific phosphorylation of rabphilin is particularly striking in view of the behavior of synapsins, which are colocalized with rabphilin on the same vesicles and are substrates for the same kinases but are still not subject to the same region-specific phosphorylation. 
CA1

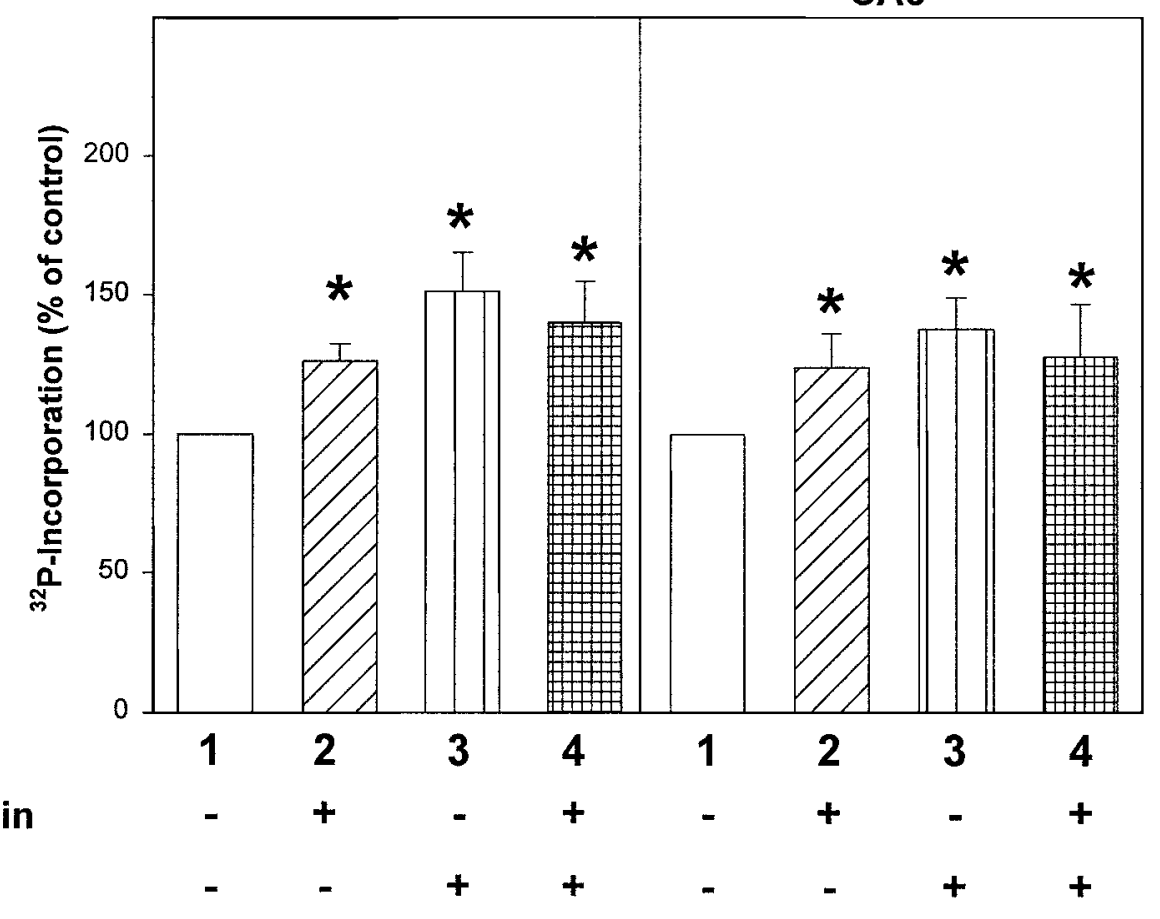

Figure 6. Modulation of synapsin phosphorylation in CA1 and CA3 synaptosomes by forskolin and $\mathrm{K}^{+}$-induced $\mathrm{Ca}^{2+}$ influx. Synapsins were immunoprecipitated from ${ }^{32} \mathrm{P}$-labeled $\mathrm{CA} 1$ or CA3 synaptosomes treated singly or in combination with forskolin and elevated $\mathrm{K}^{+}$, as described in the legend to Figure 5. Immunoprecipitates were analyzed accordingly. Data shown are mean \pm SEM from 10 independent experiments performed in duplicate; statistically significant changes are marked by asterisks.
Two questions arise: (1) What is the mechanism that allows the region-specific phosphorylation of rabphilin? (2) What does this phosphorylation mean for CA3 LTP? Although we have no definitive answer to either question at present, the fact that forskolin and $\mathrm{K}^{+}$depolarization have similar effects on synapsin phosphorylation in CA1 and CA3 synaptosomes suggests that PKA and CaM kinases are similarly present in both types of nerve terminals. Thus the selective phosphorylation of rabphilin in CA3 synaptosomes could be attributable to a compartmentalization of the kinases, a possibility raised by observations with other phosphorylation events (for review, see Faux and Scott, 1996). Alternatively, it could be attributable to differential activities of phosphatases in the two types of nerve terminals. Independent of which mechanism is operative, the net result is a differential phosphorylation state of rabphilin in the two types of nerve terminals, which thereby adds a layer of regulation on top of activation of protein phosphorylation and protein expression.

As regarding the question of the functional significance of the differential phosphorylation of rabphilin in CA3 versus CA1 synaptosomes, the correlation of this phenomenon with the selective induction of PKA-dependent LTP in mossy fiber nerve terminals (CA3 LTP) and the requirement for rab3A in the induction is intriguing. This suggests the possibility that rab3A may be required for CA3 LTP because it interacts with rabphilin and reversibly recruits rabphilin to nerve terminals (Li et al., 1994; Stahl et al., 1996). At present this possibility cannot be readily tested because forskolin has additional actions besides activating PKA and inducing LTP in mossy fiber nerve terminals (Hosi et al., 1988; Huang et al., 1995; Castillo et al., 1997). These parallel actions are unimpaired in the rab3A knock-out mice so that, although CA3 LTP can no longer be induced, forskolin still enhances neurotransmitter release. Therefore so that rabphilin phosphorylation can be correlated with LTP, studies on rabphilin knock-outs will be required. Nevertheless, the specificity for the CA3 region of the PKA-dependent phosphorylation of rabphilin and of the PKA-dependent induction of LTP is suggestive of a role of rabphilin phosphorylation in CA3 LTP. In addition, the region-specific phosphorylation of rabphilin implies that the phosphorylation states of substrate proteins can be regulated locally if the kinases and substrates are present ubiquitously, even if the substrates are colocalized on the same organelle.

\section{REFERENCES}

Castillo PE, Janz R, Südhof TC, Malenka RC, Nicoll RA (1997) The synaptic vesicle protein rab3A is essential for mossy fiber long-term potentiation in the hippocampus. Nature 388:593-598.

Faux MC, Scott JD (1996) Molecular glue: kinase anchoring and scaffold proteins. Cell 85:9-12.

Ferro-Novick S, Jahn R (1994) Vesicle fusion from yeast to man. Nature 370:191-193.

Fykse EM, Li C, Südhof TC (1995) Phosphorylation of rabphilin-3a by $\mathrm{Ca}^{2+} /$ calmodulin- and cAMP-dependent protein kinases in vitro. J Neurosci 15:2385-2395.

Garrels JI (1979) Two-dimensional gel electrophoresis and computer analysis of proteins synthesized by clonal cell lines. J Biol Chem 254:7961-7977.

Geppert M, Bolshakov VY, Siegelbaum SA, Takei K, De Camilli P, Hammer RE, Südhof TC (1994) The role of Rab3A in neurotransmitter release. Nature 369:493-497.

Geppert M, Goda Y, Stevens CF, Südhof TC (1997) Rab3A regulates a late step in synaptic vesicle fusion. Nature 387:810-814.

Greengard P (1987) Neuronal phosphoproteins. Mediators of signal transduction. Mol Neurobiol 1:81-119.

Hajos F, Wilkin G, Wilson J, Balazs R (1975) A rapid procedure for obtaining a preparation of large fragments of the cerebellar gromelruli in high purity. J Neurochem 24:1277-1278.

Hosi T, Gaber SS, Aldrich RW (1988) Effect of forskolin on voltagegated $\mathrm{K}^{+}$-channels is independent of adenylate cyclase activation. Science 240:1652-1655.

Huang Y-Y, Li XC, Kandel ER (1994) cAMP contributes to mossy fiber LTP by initiating both a covalently modified early phase and macromolecular synthesis-dependent late phase. Cell 79:69-79.

Huang Y-Y, Kandel ER, Varshavsky L, Brandon EP, Qi M, Idzerda RL, McKnight GS, Bourtchouladze R (1995) A genetic test of the effects of mutation in PKA on mossy fiber LTP and its relation to spatial and contextual learning. Cell 83:1211-1222. 
Kato M, Sasaki T, Imazumi K, Takahashi K, Araki K, Shirataki H, Matsuura Y, Ishida A, Fujisawa H, Takai Y (1994) Phosphorylation of rabphilin-3A by calmodulin-dependent protein kinase II. Biochem Biophys Res Commun 205:1776-1784.

Li C, Takei K, Geppert M, Daniell L, Stenius K, Chapman ER, Jahn R, De Camilli P, Südhof TC (1994) Synaptic targeting of rabphilin-3A, a synaptic vesicle $\mathrm{Ca}^{2+} /$ phospholipid-binding protein, depends on rab3A/3C. Neuron 13:885-898.

Li L, Chin LS, Shupliakov O, Brodin L, Sihra TS, Hvalby O, Jensen V, Zheng D, McNamara JO, Greengard P, Anderson P (1995) Impairment of synaptic vesicle clustering and of synaptic transmission and increased seizure propensity in synapsin I-deficient mice. Proc Natl Acad Sci USA 92:9235-9239.

Lisman J, Malenka RC, Nicoll RA, Malinow R (1997) Learning mechanisms: the case for CaM-KII. Science 276:2001-2002.

Martin TFJ (1997) Stages of regulated exocytosis. Trends Cell Biol 7:271-276.

Nagy A, Delgado-Escueta AV (1984) Rapid preparation of synaptosomes from mammalian brain using nontoxic iso-osmotic gradient material (Percoll). J Neurochem 43:1114-1123.

Nicoll RA, Malenka RC (1995) Contrasting properties of two forms of long-term potentiation in the hippocampus. Nature 377:115-118.

Rosahl TW, Geppert M, Spillane D, Herz J, Hammer RE, Malenka RC, Südhof TC (1993) Short term synaptic plasticity is altered in mice lacking synapsin I. Cell 75:661-670.

Rosahl TW, Spillane D, Missler M, Herz J, Seling DK, Wolff JR, Hammer RE, Malenka RC, Südhof TC (1995) Essential functions of synapsins I and II in synaptic vesicle regulation. Nature 375:488-496.

Salin PA, Malenka RC, Nicoll RA (1996) Cyclic AMP mediates a pre- synaptic form of LTP at cerebellar parallel fiber synapses. Neuron 16:797-803.

Sheperd GM (1990) The synaptic function of the brain, 3rd Ed. New York: Oxford UP.

Shirataki H, Kaibuchi K, Sakoda T, Kishida S, Yamaguchi T, Wada K, Miyazaki M, Takai Y (1993) Rabphilin-3A, a putative target protein for smg p25A/rab3A p25 small GTP-binding protein related to synaptotagmin. Mol Cell Biol 13:2061-2068.

Spillane DM, Rosahl T, Südhof TC, Malenka RC (1995) Long-term potentiation in mice lacking synapsins. Neuropharmacology 34:1573-1579.

Stahl B, Chou JH, Li C, Südhof TC, Jahn R (1996) Rab3 reversibly recruits rabphilin to synaptic vesicles by a mechanism analogous to raf recruitment by ras. EMBO J 15:1799-1809.

Stevens CF (1993) Quantal release of neurotransmitter and long-term potentiation. Cell 10:55-63.

Südhof TC (1995) The synaptic vesicle cycle: a cascade of proteinprotein interactions. Nature 375:645-653.

Terrian DM, Johnston D, Claiborne BJ, Ansah-Yiadom R, Strittmatter WJ, Rea MA (1988) Glutamate and dynorphin release from a subcellular fraction enriched in hippocampal mossy fiber synaptosomes. Brain Res Bull 21:343-351.

Wang JKT, Walaas SI, Greengard P (1988) Protein phosphorylation in nerve terminals: comparison of calcium/calmodulin-dependent and calcium/diacylglycerol-dependent systems. J Neurosci 8:281-288.

Wang Y, Hofman K, Südhof TC (1997) RIM: a putative Rab3 effector in regulating synaptic vesicle fusion. Nature 388:590-593.

Weisskopf MG, Castillo PE, Zalutsky RA, Nicoll RA (1994) Mediation of hippocampal mossy fiber long-term potentiation by cyclic AMP. Science 23:1878-1882. 